\title{
LES NOVES FORMES DE «L'ESCOLARITAT» DE MASSA
}

Giotgio Franchi

(CISEM, Milà)

\section{MODALITATS DE L'ESCOLARITAT I SISTEMES \\ DE FORMACIO POSTOBLIGATORIA: UNA LECTURA DE CONJUNT}

\subsection{Els fenòmens més recents}

És indubtable que allò que caracteritza, des de fa alguns anys, la formació postobligatòtia és el canvi. Estem, efectivament, davant d'una sèrie de transformacions petites $i$ grans: entre elles algunes han estat advertides i discutides (parcialment), però és necessari que siguin més ben liegides, analitzades $i$ interpretades, també perquè moltes d'elles s'expressen actualment a nivell de tendències $i$ presenten aspectes els significats dels quals és sovint més qualitatiu que quantitatiu.

Quins són, esquematitzats al màxim, aquests canvis?

El primer ens és donat per l'augment de les activitats de formació postobligatòria: activitats formals (escola, formació professional), activitats menys formals (cursos de diferent mena i duració), oportunitats d'entiquiment cultural i formatiu ofertes per la societat, etc. Totes les anàlisis estan d'acord amb aquesta dada; el paper de la formació dins de la societat contemporània ha augmentat progressivament, encara que el símptoma més gran d'aquest augment sembla ésser constituit pel desenvolupament de l'extraescola (entesa sobretot en el seu sentit més ampli), més que per l'escola entesa de manera tradicional. 
L'escenari resulta, doncs, sensiblement diferent respecte al passat: més ric d'oportunitats, més variat respecte a les necessitats i funcions, més comprensiu cap a les possibles exigències.

En tot això no hi ha diferència entre Itàlia $i$ els altres paisos europeus occidentals: canvia la fenomenologia específica de les modificacions segons les distintes estructures dels sistemes formatius, però els fenòmens i les tendències són els mateixos; més encara: pertot arreu, i més que a Itàlia, les recents intervencions de política educativa s'han decantat cap al cantó que podríem anomenar extraescolar. Es tracta d'una observació important petquè és testimoni de fenòmens generalitzats i d'una problemàtica evidentment ni específica ni conjuntural.

Un segon canvi deriva de la relació entre escola i treball. Malgrat que aquesta relació no hagi estat mai exaltant, és indubtable que s'ha anat deteriorant progressivament, fins al punt que seria millor parlar de no-relació entre els dos moments. El saldo ocupacional positiu es refereix a un percentatge minoritari dels diplomats (de menys d'un terç a menys de la meitat, segons les distintes branques) i dels ilicenciats. Hi ha, especialment, una no-correspondència creixent entre la branca d'estudi escollida i l'eventual posició ocupacional. Per a allò que es tefereix a l'escola, el canvi més gran consisteix en l'extensió de les anomenades «posicions mixtes d'estudi i de treball», o sigui en aquella que podríem definir com una anticipació de la recerca de treball durant els estudis (abans, doncs, de l'obtenció d'un títol d'estudis). Una anticipació que al mateix temps assenyala l'existència de «noves modalitats» de relació - i de nova composició- entre experiència formativa $i$ de treball (sigui el que sigui), parcialment advertides i poc estudiades fins avui en dia. ${ }^{\mathrm{I}}$

Al mateix temps s'ha de fer constar la importància creixent de les activitats formatives dirigides als qui ja treballen, especialment aquelles aptes a permetre mobilitat intersectorial $i$ interempresarial. Aquí es posa en evidència una funció nova per a la formació, destinada, cada vegada més, a esdevenir estructural: aquestes necessitats $i$ aquestes intervencions poden, efectivament, resultar sobrerepresentades en determinats moments conjunturals marcats --com acostuma a succeir avui- per intensos processos de crisi i reestructuració, tant de tecnologia com d'organització, i per l'escassetat d'ocasions de treball, petò les motivacions de fons que els determinen s'han de considerar com a dades ja permanents. Aquí hi ha un problema

1. Em sembia que els estudis més significatius al respecte són els realitzats en la zona de Milà i Bolonya. Vegeu: L. Frey, «Le figure miste e la problematica occupazionale en provincia di Milano», a Cisem, Formazione post-obbligatoria, Primo rappor* to sulla situazione formativa, Angeli, Milano, 1983; V. Capecchi, Prima $e$ dopo it di* ploma: percorsi maschili e femminili, Il Mulino, Bologna, 1983. 
que ens hem de plantejar tot seguit: aquestes intervencions responen a necessitats específiques i presenten en el pla educatiu unes característiques igualment específques, però és veritat que, al mateix temps, podran (més encara, segons el meu parer, hauran de) tenir influències sobre l'escola - sigui, la formació primera- i sobre la manera de concebre, en general, i organitzar la instrucció i la formació després de l'escolatitat obligatòria.

Un tercer canvi està constituit pel nou funcionament intern de l'escola, per les noves relacions entre escola i qualsevol aitra formació postobligatòria, i pels camins transversals, suma de diverses freqüències, que s'evidencien sempre més dins del sistema, encara que sigui —com ja es deiaa nivell de tendència. Són coses que analitzaté amb més detall més endavant.

\subsection{El nou escenari de la formació postobligatòria dels anys vuitanta}

El conjunt d'allò que hem vist fins ara ens presenta, tal com ja hem dit, un nou escenari de la formació postobligatòria dels anys vuitanta, un escenari que convé especificat millor, encara que sigui de manera molt esquemàtica.

Quines són les característiques i al mateix temps els problemes nous que aquest conjunt ens proposa? Esquematitzant-la al màxim, podem elaborar aquesta primeta i provisional llista.

a) Dins dels diversos fenòmens hi ha, en primer lloc, una tendència cap a la negació de la «separació» entre instrucció/formació/vida activa. En allò que succeeix -efectivament- hi ha present una forta exigència d'enLlaços concrets, de nous equilibris entre experiències institucionals, culturals i de treball. Tot això es manifesta avui en dia de manera no sempre cristallina, per la senzilla raó que les noves necessitats ensopeguen amb l'estructura donada del sistema de formació; però si es pogués fer-ne abstracció, no seria difícil trobat en els diversos fenòmens molts dels taonaments/ objectius que caracteritzen el contemporani debat pedagògic (per entendre'ns, el que s'ha desenvolupat des del «Rapporto Faure» en endavant): la idea i la pràctica de l'educació com a procés continu, la necessitat de construir formes «alternatives» entre escola i treball, l'exigència de personalitzar els camins formatius, etcètera.

b) Probablement és dins d'aquest matc on es colloca el desenvolupament de l'extraescola, en el sentit que és cap a aquest sector (exttemament variat, a més a més, pet la seva naturalesa) on es centra la demanda de 
novetat que difícilment podia ésser oferta per l'escola. Però és oportú distingir, àdhuc per comprendre millor. No es pot oblidar la sensació, per exernple, que una part de l'extraescola ha crescut en directa correspondència amb l'immobilisme de l'escola i amb les seves mancances cada cop més evidents. Així -amb I'intent d'exeraplificar, encara que sigui difícil estâblir línies de demarcació-, és en aquesta clau que pot ésser explicat el desenvolupament de les activitats relatives a l'ensenyament de les liengües estrangeres o d'aquelles dirigides a especialitzacions professionals «noves». Però, repeteixo, és difícil definir dràsticament tipologies: algunes «especialitzacions», així com alguns ensenyaments, tequereixen metodologies, duració i característiques no escolars; si el fort desenvolupament d'aquestes activitats es beneficia, doncs, de l'absència d'aquells ensenyaments a l'escola, és igualment veritat que sovint és correcte que aquelles intervencions siguin dutes a terme de forma específica. En altres casos l'oferta, declaradament, té el sabor de camins escolars escurçats, quan no es presenta com un miraculós (i moltes vegades enganyós) passaport per a l'ocupació. I tampoc no es pot, com a observació general, fer desaparèixer la sensació que aquest desenvolupament correspon també a la tendència a organitzar (però també a «segregat») tot el temps lliure, tal com remarca E. Becchi, pel que es refereix a la vida de l'infant.

Però més enllà de tot això —que malgrat tot queda i s'ha d'analitzascrec necessari subratllar funcions més generals, i en aquest cas «noves», que l'extraescola desenvolupa al marge, per dir-ho d'alguna manera, de contingències especials: em refereixo a l'enriquiment cultural més completiu, a la satisfacció de necessitats cognitives individuals, a l'especialització dels curriculums escolars, a l'adhesió més profunda a la realitat. Tot això correspon, per una banda, a l'increment de demanda de «cultura» i, per l'altra, a l'exigència d'intervencions breus, flexibles, aptes, dins de llur especificitat, per a portar a resultats ais quals unir-ne, o més senzillament, afegir-ne uns altres, segons les necessitats, i així successivament. $\mathrm{Hi}$ ha, a més a més, una ulterior funció de l'extraescola - de la qual tornaré a parlar més tard- - que opino que és de gran importància: la de permetre la «personalització $\mathrm{i} / \mathrm{o}$ diversificació» dels títols d'estudis, cosa aguditzada pel fet que avui aquests títols estan superats respecte als canvis esdevinguts en el mapa de les figures professionals. Però aquesta funció està destinada a romandre (i fins a manifestar-se sempre més) dependent de l'elecció «polivalent» que es vulgui dur a terme amb la nova escola secundària superior, $i$ de les mateixes transformacions de les figures professionals i del concepte de professionalitat, que davant d'una segura i àmplia formació «polivalent» requereixen «especialitzacions» destinades a canviar tàpi- 
dament en el temps, fàcilment reconvertibles $i / o$ reciclables, $i$ això successivament. ${ }^{2}$.

c) Finalment, com a problema més general; hi ha aquell de les noves formes del coneixement contemporani, dels increibles canvis que s'estan verificant en aquest camp. Es suficient recordar la revolució en el camp de la informàtica, el nou paper que la informació està assumint: la quantitat d'informacions que s'ha de posseir, el seu flux rapidíssim, la manera de temuntat a les fonts, de tractar i comprendre les informacions, són tots fets que replantegen el paper tradicional de l'escola, que demanen rapidesa i flexibilitat de coneixement, etcètera.

Encara que sigui provisional i esquemàtica, la llista hauria d'haver aclarit que la configuració actual del sistema de formació respon a problemes reals, a exigències i necessitats que estan destinades a ésser profunditzades ulteriorment. En la seva fenomenologia actual, els diversos, diferents i contradictoris desenvolupaments donen per cert - tal com he afirmat moltes vegades- l'immobilisme de la política escolar i la situació de crisi econòmica i ocupacional; són, a més a més, fruit de moviments espontanis i de la «liture» lògica de metcat: «petò corresponen a necessitats concretes».

L'operació que s'ha de posar a l'ordre del dia és aquella d'analitzar-ho tot en detall; entendre quant hi ha de sobreposició i d'excés, per entendre al mateix temps el fet nou i reflexionar sobre les formes més correctes dins de les quals gestar-1o.

Si per cas no ho he sigut prou, vull ésser clar fins al fons: aquest és l'escenari que caracteritza la formació, avui i demà. La «seva forma» actual pot ésser «judicada», la substància dels problemes que ens proposa pot ésser «compresa $i$ organitzada».

2. Entre els diversos estudis sobre les transformacions que tenen lloc dins de l'organització del treball $i$ en la professió, poden ésser mencionats: F. Butera, Le ricerche per la trasformazione del lavoro industriale in Italia: 1969-1979, Angeli, Milano, 1981; F. Butera, «Organizzazione del lavoro e professionalità nell'industria», "Quademi Isfol», núm. 17; F. Chiaromonte, Sindacato, vistrutturazione, organizzazio. ne del lavoro, Esi, Roma, 1978; S. Mollica, P. Montobbio, Nuova professionalitd, formazione $e$ organizzazione del lavoro, Angeli, Milano, 1982. Una sintètica traduccio d'aquesta temàtica en clau formativa és de G. Franchi, Formazione post-obbligatoria $e$ professione; de V. Ariosi, F. Frabboni, V. Telmon, La scuola secondaria: riforma, curricolo, sperimentazione, Il Mulino, Bologna, 1981. 


\subsection{Problemes d'interpretació}

Ja tenim matèria més que suficient per a plantejar-nos alguns problemes interpretatius. El quadre sumàriament dibuixat ens posa davant de tres qüestions. La primera, una reducció també quantitativa de l'escola respecte al conjunt dels instruments formatius: com a mínim -hom diu- aquesta creix menys que abans; la segona, una reducció, en aquest cas qualitativa, de l'escola, encerclada i objecte d'intensa concurrència per part d'intervencions formatives més modernes (més breus, flexibles i fins més específques i «apetibles») i més generals per part dels moderns mitjans $i$ instruments informatius als quals el jove (el ciutadà) pot fàcilment tecórrer; la tercera, una objectiva reducció del pes que la instrucció (i especialment l'escola) desenvolupa en la relació amb la possible ocupació.

En les pàgines següents intentaré realitzat una comprovació més atenta d'aquest quadre, però no es pot pas negar que presenta més d'una resposta real. I és precisament sobre aquesta base que s'ha anat conformant una intexpretació que es converteix en preeminent, encara que sobre ella no s'hagi desenvolupat cap debat específic. Intentaré sintetitzat aquesta interpretació. ${ }^{3}$

L'escola està perdent el seu centralisme: ja no és el lloc on es reben les informacions $\mathrm{i}$ els coneixements; al seu costat existeixen instruments $\mathrm{i}$ mitjans que poden oferir no sols els mateixos, sinó en alguns casos encara més informacions i coneixements; a més a més, tan aturada com està l'escola des de fa temps en l'ordenació, en els programes, en els continguts, no ens hem de meravellar si es recorte cada vegada més a intervencions formatives «diferents», decididament més àgils, que utilitzen sovint tecnologies més avançades, amb èxits més definits, i que representen fins i tot l'ingrés (o el reingrés) dins de la instrucció de la «sana» empresa priva$\mathrm{da}$; i afegiríem, atès que és veritat, que la professionalitat pot ésser adquitida especialment, per no dir sols, amb i en el treball; que és inevitable que es desenvolupin moments-pont entre escola $i$ treball $i$ encara més de formació en el treball, $i$ així successivament.

Donades aquestes motivacions - hom diu-, no ens hem de meravellar si els usuaris fan «tries» cada vegada més determinades $i$ es disposen d'una

3. La interpretació a la qual em refereixo és l'elaborada pel Censis, tal com va ésser reconstruìda a través de la lectura dels capítols sobre la instrucció en els Informes relatius a la situació social del país el 1981, el 1982 i el 1983.

L'elaboració del Censis és en realitat molt més rica i problemàtica del que podrà semblar en la meva reduïdíssima síntesi, que té en compte especialment la traducció «vulgar» que se n'ha fet, oblidant molt aviat el caràcter d'important contribució científica que les anàlisis del Censis tenen sempre. 
manera nova dins del sistema de formació, i si el sistema, de part seva, està configurat conseqüentment amb aquestes tries. El resultat final del raonament - que he simplificat intencionadament- es converteix en la legitimació de l'actual configuració del sistema formatiu, constituilt per tres sectors: l'escola, i més en general la distribució formal de la instrucció; l'extraescola; la formació cap a i en el treball. Sectors en molts aspectes autònoms un de l'altre, considerats — dins de la interpretació completivaquasi equivalents entre ells, i dels quals es considera necessàriament l'ulterior desenvolupament d'aquesta interpretació -trobar i construir un equilibri recíproc 0 , encara millor, un «arbitratge a tres pols».4

El punt central del raonament és la contracció (relativa) o l'estabilització dels índexs d'escolaritat i dels moviments escolars; efectivament, és sobre la base d'aquesta dada que els altres desenvolupaments són carregats de valences «institucionals» o, millor, dels atributs de sectors. Era important subratllar aquest aspecte, perquè en cas contrari és difícil no estar d'acord amb l'anàlisi, diguem-ho així, qualitativa, o sigui aquella que descriu l'ampliació de les necessitats formatives i remarca l'exigència d'instruments amb característiques diferents de les escolars.

Dèiem abans que aquesta lectura no ha estat sotmesa a una veritable discussió: el que ha passat, potser, ha estat l'acceptació passiva $i$, encata més, l'exageració dels resultats; $o$, al contrati, el que pot ésser considerat com una correcció de les possibles consequiències de la lectura mateixa.

D'aquesta manera, la "pèrdua de centralisme de l'escola» en favor d'altres instruments ha estat emprada per considerar com a cada vegada més «marginal» el paper de l'escola i especialment el de «l'escola pública»; sobre aquesta base s'ha intentat legitimar la substitucio, esdevinguda en tots aquests anys, de la «política» escolar per l'«administració» escolat, per una banda; la possibilitat d'una privatització de l'escola, per l'altra; i finalment, la propostâ d'una liberalització completa del mercat escolat i educatiu. I és inútil la posició expressada recentment per la Democràcia Cristiana. En canvi, en oposició, hi ha la línia del Partit Comunista, codificada en la seva IV Conferència Nacional, que respon a la lògica del «sisterna educatiu ampliat» (o sigui, senzillament a la constatació de l'existent) amb la necessitat de definir relacions i lligams entre els diferents moments, amb la construcció d'un «sistema integrat» amb l'escola en el seu centre.

4. Vegeu al respecte el pròleg amó títol «Atbitraggio a trepoli», de G. De Rita, en el núm. 14 (nova sèrie) del «Quindicinale di note e commenti» del Censis, dedicat totalment a la problemàtica formativa.

5. Pel que fa a la posició de la DC, és visible essencialment en alguns discursos del seu secretari De Mita (fet que dóna testimoni del relleu polític que la DC 
Cal afegir que la finalitat d'aquestes pàgines no és la d'endinsar-se en el debat polític, sinó més aviat la de contribuir a una lectura més profunda dels fenòmens en acció en la formació postobligatòria.

I això per dos motius. El primer, que hauria d'haver quedat ben clar, pet les coses afirmades en el paràgraf 1 , que jo estic convençut que estem en presència de transformacions profundes en allò que es tefeteix no sols a la disposició del sistema educatiu, sinó també a la definició i al paper mateixos de la formació: transformacions que tenen necessitat d'anàlisis atentes i de l'obertura d'un debat específic, abans d'ésser tecondüdes massa tàpidament a sintètiques solucions polítiques. $\mathrm{El}$ segon, que hi ha diversos punts en l'anàlisi $i$ en la interpretació presentats que em semblen superfrcials $i$ que, considerats més bé, podrien dur-nos a conclusions bastant diferents almenys en el pla de les possibles conseqüències operatives. In. tento, doncs, considerar novament la part de l'anàlisi que es refereix als desenvolupaments escolars, pel relleu que té dins del suport completiu de la lectura mencionada abans i perquè és aquella de la qual més dades es tenen. L'anàlisi -donada la natura d'aquestes pàgines- serà sintètica. En les notes a peu de pàgina el lector podrà trobar les fonts en les quals es basen els diferents raonaments.

\subsection{Una segona lectura dels desenvolupaments escolars}

La referència és envers l'escola superior secundària, diürna o nocturna, pública o privada, i la formació professional de primer nivell (o sigui el sector formal, institucional, de l'educació).

La dada inicial és la imatge contradictòria que ens diu que, d'una ban$\mathrm{da}$, ha augmentat en el pla quantitatiu i qualitatiu el pes de l'educació, i de l'altra que s'ha reduït (en termes relatius) el pes de l'escola. Si efectivament considerem L'index d'escolaritat completiu, resulta substancialment estable des de fa 5-6 anys, verificat sobre un valor relativament alt (el $53 \%$ aproximadament), semblant al de la situació europea.

ofereix al seu «nou» discurs sobre la instruccio), entre ells l'informe en l'últim Congrés Nacional del Partit.

Els mesos de febrer i març hi ha hagut, a més a més, les dues conferències nacionals sobre l'escola del PSI i del PCI, centrades, la primera en els nous camins formatius ampliats, presents en els actuals desenvolupaments, i la segona sobre la proposta del sistema formatiu integrat: raonament que dins de la IV Conferència Nacional del PCI hom ha aftontat amb una gran amplitud d'implicacions tant pel que es refereix al nivell nacional com a l'europeu. En ambiós casos la documentació està constituïda per material ciclostilat. 
Després d'afirmar de nou que en aquest fenomen juguen objectivament algunes de les coses dites anteriorment, hi ha un nus que em sembla que sempre s'ha deixat de banda: «o sigui que quant més creix l'escolarització, més s'eixamplen les necessitats i la demanda de formació ulterior», tal com ba estat demostrat per nombroses investigacions a nivell internacional i nacional.' Dit d'una altra manera, el desenvolupament de l'extraescola es podria explicar «també» com una consequiència de l'escolarització total: com un "efecte», doncs, de l'expansió de l'escolaritat, que ha convertit en evidents i explícites les necessitats educatives, amagades anteriorment.

Però es podrà objectar que l'escolaritat en la secundària superior està aturada des de fa uns anys, encara que sigui molt alta $i$ continuï essent l'escola el sector educatiu decididament més gran: en aquest cas el desenvolupament de l'extraescola marcaria també tries diferents respecte a l'educació. Però és veritat que l'escola està aturada? ¿ $\mathrm{O}$, potser, han canviat tant el «funcionament» de l'escola i del sistema educatiu com les maneres de «seguir i utilitzar» el sistema?

Les dades generals relatives a l'escola secundària superior ens colloquen davant d'una imatge, ella també, contradictòria: en considerar l'índex d'escolaritat calculat en aquests cinc anys, resulta pràcticament estacionari des de 4-5 en endavant. Malgrat això, si considerem el mateix índex en relació amb els primets anys de la secundària superior, constatem que està augmentant de manera constant i sensible, tant, que és possible afirmat que estem molt a prop d'un objectiu perllongament dels anys d'estudis obligatoris en un o dos després de la licenza media ${ }^{* 7}$ (dada verificada ulterior-

6. Exemplar, al respecte, és el cas francès, després de l'aprovació, el 1971, de la llei sobre la formacio contínua. Després d'alguns anys d'aplicació, els subjectes que majorment havien utilitzat les intervencions formatives de teciclatge eren aquells que ja possejen nivells d'escolarització mitjans o mitjans-alts. Cfr. P. Albe, M. Todeschini, «Francia. Una scuola bloccata in una società bloccata», a G. Franchi, M. Tedeschini, La titorma in Europa, Isedi, Milano, 1987; Isofol, «Francia/Congedi di formazione», «Quaderni di formazione Isofol», núm. 32.

* N. del Trad.: 8z. d'EGB.

7. Poden bastar poques dades. Ies taules setan presentades al final del treball.

L'índex de pas entre la III media i la I media superior ha tingat el moviment indicat en la taula 1; les seves dades demostren, a més a més, que el fenomen s'ha accentuat, i molt sensiblement, en els darrers tres anys. Molt indicatives són les dades de la t. 2, que marquen el moviment de t'index d'escolaritat deis joves de 14 anys en l'escola secundàtia superior dins de la província de Mità.

Com a testimoni no sols de la tendència, sinó de la seva accentuació en els datrets anys, se'ns presenta la situació d'una realitat, la de la província de Ravenza, en la qual els indexs d'escolaritat eren ja molt alts $(77,5 \%$ el 1973-74) en la primera mei- 
ment si es consideren els inscrits a la formació professional regional «de base», jovent de 14-16 anys que «viu» la formació professional com una escolarització més breu). ${ }^{g}$

No és veritat, doncs, que disminueixi la propensió cap a l'escola. Al contrari, des del punt de vista de la continuació després de l'escola bàsica, aquesta propensió està augmentant constantment, i hi ha una tendència molt estesa a continuar els estudis segurament per un any més, però també per més temps, com dos o tres anys.

És necessari explicar la contradicció entre els dos índexs. Efectivament, la dada nova és que han augmentat notablement les «tenúncies» durant els cicles d'estudis de l'escola secundària, amb un moment especial en el pas del primer/tercer any. O sigui que és veritat que entren més alumnes a les escoles, però també són més aquells qui les deixen irregularment. ${ }^{9}$

Aquest fenomen de les tenúncies encara s'ha d'analitzar totalment; pot ésser accentuat pel fet que, en ampliar-se cada vegada més l'escolaritat, entra a l'escola un tipus de població escolar precedentment exclosa de la instrucció superior, que presenta, doncs, un risc més gran de fracàs escolar; pot demostrar de manera vistosa la distància entre batxillerat inferior $\mathrm{i}$ superior; pot indicar una «tria» real per part dels usuaris i així successivament. Probablement els diversos factors es barregen entre ells. Entre aquests, a més a més, no hem d'oblidar la situació de crisi econòmica i de llocs de treball que empeny, segons sembla, molts joves estudiants, espe-

tat del anys 70 (t. 3). El que s'ha de remarcar és el valor -pròxim a la totalitatde l'índex d'escolaritat el 1981-82: el 84,2\%.

A les dades presentades, shaurien d'afegir les dels inscrits a les formacions pro fessionals de base. Desgraciadament les investigacions en aquest sector no permeten informacions exactes $i$ sols per als darrers anys hom pot disposar de dades relativament homogènies (cfr. Rapporto Isofol 1982 sulla formazione professionale in Italia, Angeli; Milano, 1983; Rapporto Isotol 1983 sulla formazione professionale in Italia, Angeli, Milano, 1984).

Com a nivells de senzilla estimació (i subvalorant eis fenòmens), a les dades relatives a la província de Milà hom pot afegir un ulteriot $10-12 \%$, i a les de la província de Ravenna un uiterior 8-10\%.

8. Al respecte, així s'expressa el Rapporto Isofol 1983, cit.: «La investigació 1981-82 confirma la tendència ja posada en evidència per la de 1978-79 d'una baixada de l'edat mitjana dels alumnes: passa de 17,0 el 1979 a 16,3 el 82: es confirma, doncs, la tendència a un pas més directe des de l'escola a la formació professional i per tant a la utilització d'aquesta última com a canal professional per a l'accés directe al mercat del treball.»

9. El fenomen és ja violt conegut. Per illustrar-lo sintèticament, són molt indicatives les taules 4 i 5 , tretes del núm, 2, 1984, de «Cisem/Informazioni». 
cialment nois, a «treballar» durant els anys d'estudis, i a deixar, doncs, els estudis si el «treball» que estan fent és segur. ${ }^{10}$

De totes maneres, és un fet que la baixa de l'index d'escolaritat en la totalitat dels cinc anys «amaga un procés d'escolaritat posterior» que, si es té en compte l'augment de la propensió cap a l'anomenat «cicle curt» (cursos de formació professional de base), es refeteix pràcticament a un trienni postobligatori.

Petò s'ban de considerar també d'altres aspectes. Juntament al fenomen de les «renúncies» irregulars, hi ha el d'un moderat «retorn» a I'escola, que generalment és realitzat a través de les escoles no estatals (diürnes i nocturnes); en aquest sentit, la seva especialització s'ha anat accentuant notablement en aquests últims anys. Poden, també, ésser "retorns impropis», que consisteixera en el pas de la secundària supetior als mòduls terminals de la formació professional regional (hem de recordar que els estudiants de formació professional que vénen de l'escola secundària amb alguns anys de freqüència són un tant per cent —en augment constantpròxim al 25). Aquest pas permet consolidar una certificació formativa, en aquest cas en el terteny de la formació professional.

Volem dir que, si d'una banda augmenten les tenúncies, això no significa sempre $i$ en tots els casos interrupció de l'escolaritat: aquesta sovint és recuperada i acabada, encara que sigui amb formes, modalitats, temps,

10. Sobre el problema de la dispetsió escolar, les contribucions més interessants semblen ésser les següents: com a punt de referència, encara que les dades hagin envellit una mica, pot ésser útil: M. Gattullo, «L'andamento della selezione scolastica italiana», «Inchiesta», núm. 23, 1976, pp. 52-60. Una contribució més actualitzada és: L. Bernardi, «Scolarizzazione e selettività del sistema scolastico italiano», a S. Sarpellon, La povertì in Italia, Angeli, Milano, 1982.

Pel que fa referència a les recerques específiques sobre el problema de les tenúncies escolars, vegeu: Censis, I drop-outs della secondaria, 1976, cicl. Una exposició sintètica dels principals resultats de la recerca es pot trobar a «Annali della pubblica istruzione», núm. 1, 1978, pp. 31-44; Censis, "Quindicinale di note e commentì, núm. 293, 1978, pp. 540-547, i núm. 303, pp. 988-991; Università Cattolica del Sacro Cuore, Istituto di sociologia, Determinazione di metodi per lo studio del fenomeno degli abbandoni nella scuola secondaria superiore, 1981, cicl., Cnos-Fap Verona -Università pontificia salesiana di Roma, Istituto di sociologia della Facoltà di scienza dell'educazione, L'abbandono nel biennio della scuola secondaria superiore nel comune di Verona, 1982, cicl (una presentació sintètica dels resuitats de la recerca es troba a: «Orientamenti pedagogici», núm. 29, 1987, pp. 798-816); E. Pugliese, I giovani tra scuola e lavoro nel Mezzogiorno, Angeli, Milano, 1982.

Una discussió general del problema, àdhuc d'una sintètica però puntual iłustració de tes recerques mencionades, es troba a R. Pasini, G. Librando, «La dispersione scolastica nella scuola secondaria. supetiore» «Cisen/informazioni», núm. 2, tnarç de 1984. 
diferents dels "normals». ${ }^{\text {in }}$ Potser bem de refiexionar sobre aquestes noves formes de l'escolaritat de massa, sobre les noves maneres de passar per l'escola.

Com a confirmació de la legitimitat d'aquesta lectura, hi ha l'observació dels canvis esdevinguts en el funcionament de tot el sistema escolar «ampliat» (estatal o no estatal).

Estem assistint, efectivament, a progressives especialitzacions dels difetents moments escolars/formatius no estatals, que acaben intervenint cada vegada més en correspondència amb els fenòmens nous en acció a l'escola secundària superior estatal. Serveixen cada vegada més com a "recuperació»" de l'escolaritat interrompuda a l'escola estatal i cada vegada menys com a oportunitat escolar parallela. Es tracta de constatacions fàcils de verificar, malgrat que encara s'hagi de fer una anàlisi puntual del funcionament de tot el sistema (i especialment s'hagi d'《atestar» l'anomenada aproximació «de sistema», l'únic capaç d'explicar-nos el que passa i de suggerir hipòtesis correctes d'intervenció).

De les poques coses que acabem de dir surt un quadre una mica diferent de la versió simplificada de «pèrdua de centralitat de l'escola». En realitat no és veritat que hagi disminuït la demanda d'escola per part dels

11. Una quantificació exacta del fenomen dels «tetorns» és difícil, encara que es pot referit -com recorda $V$. Cesareo en el seu treball citat més avall- «a quasi el $5 \%$ de la nostra població escolar total».

Encara més complex és oferir un quadre quantitatiu teal deis passos entre secundària superior i FP, especialment perquè les dades nacionals són velles. A la t. 6 presentem les dades de la investigació Isofol/regions, efectuada l'any formatiu 1978-79.

Investigacions més properes en el temps -efectuades segons el mateix plantejament- - ofereixen un quadre en què les tendències s'han profunditzat.

Així, per exemple, a la província de Ravenna, l'any educatiu 1982-83 el percentatge dels inscrits a FP després d'haver freqüentat alguns anys l'escola secundària superior exa del $26 \%$ aproximadament, mentre que la mateixa dada a la província de Piacenza era aproximadament el $34 \%$. Són simptomàtiques, en ambdós casos, les dades relatives a aquells que han anat un 0 dos anys a la secundària superior: al voltant del $22 \%$ a Ravenna i el $31 \%$ a Piacenza. (Fonts: província de Ravenna, Ls formazione professionale di base in provincia di Ravenna, 1983, cicl.; província de Piacenza, L'evoluzione della formazione post-obbligatoria in provincia di Piacenza 197282, 1983, cicl.).

Per retornat al problema general mel del fenomen de les sortides i dels successius «retorns" amb acabarnent dels estudis-, són de gran interès els resultats obtinguts en la recerca efectuada sobre un mostrari de 4.000 joves pel Iard en collaboracio amb la Doxa. En ella s'afirma que, entre aquelis que han abandonat els estudis en el postobligatori, el $61,6 \%$ (o sigui la gran majoria) ha obtingut més tard una certifica. ció professional o un diploma de cicle curt (cfr.: V. Cesareo, «Processi ed esperienze nella scuolas, a A. Cavalli, V. Cesareo, A. De Lilto, R. Ricolf, G. Romagnoli, Giovoni oggi, Il Mulino, Bologna, 1984, p. 26). 
joves, sinó tot el contrari. S'ha anat, més aviat, obrint camí una actitud més «econòmica» $i$ «utilitarística» envers l'escola; hi ha una dispersió escolar més gran (si bé dins d'una major escolaritat), però també un retorn escolar més gran (en sentit determinat i extensiu).

En altres termes, es pot dir que els processos d'escolaritat estan creixent, encara, $i$ que al mateix temps ha canviat i està canviant la manera de seguir els cicles escolars. Abans de tot, hom escull els més curts per consolidar en temps ràpids una certificació escolar. En segon lloc, per a un grup sempre creixent de joves, la consecució d'un diploma (i postetiorment fins i tot la llicenciatura) s'obté en temps més llatgs del normal, a vegades després d'haver passat per experiències educatives i de treball.

D'això resulta no sols un aprofundiment dels índexs, ja alts, d'escolaritat en els primers anys d'escola secundària superior, sinó també un augment general de l'escolarització i de la possessió dels títols finals, obtinguts amb temps i modalitats diferents.

Dins d'aquest marc s'ha de plantejar la qüestió de l'extraescola. És oportú aclarir tot seguit un punt: aquell qui freqüenta aquestes activitats és, en gran part, aquell mateix que va freqüentar $\mathrm{i} / \mathrm{o}$ freqüenta l'escola. Es tracta, doncs, de posicions que sovint es barregen entre elles, no d'usuaris decididament diferents.

Evidentment les funcions que exerceix l'extraescola són - com ja he recordat abans-m moltes i variades, incloses algunes que responen a exigències absolutament subjectives; però juntament o dins d'aquestes sembla molt persuassiva i s'ha de subratllar amb força, puix que avui està completament oblidada, la de «diferenciar» certificacions escolars que, d'una banda, són poc corresponents a la realitat $i$, per l'altra, són ja possessió dels joves.

Per exemple, els ragionieri * ja són molts, però els ragioneri que saben informàtica, que coneixen diferents llengües estrangeres, que ja han realitzat -encara que sigui de manera esporàdica- una experiència de treball en aquest sector, són molts menys. I aquesta necessitat de diferenciació és molt més acusada quan se sap que les ocasions de treballar són poques i que la concurrència en el mercat del treball és gran.

Pot ésser oportú profunditzar els raonaments fets fins ara i analitzar, encara que sigui superficialment, els diversos comportaments que estan duent a terme els nois $\mathrm{i}$ les noies, respectivament, dins de la formació postobligatòria." En primer lloc, en els darrers anys l'augment de l'índex d'escolaritat en l'escola secundària superior ha estat determinat per l'ingrés

* N. del Trad.: Títol que correspon a perit mercantil.

12. Entre les contribucions més interessants sobte aquesta temàtica, encara massa poc analitzada, vegeu: V. Capecchi, Prima e dopo il diploma, cit. 
de les noies a l'escola; elles oferien, respecte als nois, un índex d'escolaritat decididament més baix. Per als nois, al contrari, anar a l'escola després de l'etapa obligatòtia és una conquesta de $\mathrm{fa}$ ja alguns anys, al mateix temps que la de la possessió del títol de secundàtia superior. En segon lloc -en estreta coherència amb allò que acabem de dir- és el comportament masculí aquell que «fa ús», en discontinuitat, de l'escola (sortides i retorns de diversos tipus, ja esmentats). El comportament femení resulta, efectivament, molt més «regular» en el seu tecorregut escolar, tant si és de «cicle breu» ( $\mathrm{i}$ és forta aquesta propensió per part femenina, com a demostració d'expectatives més limitades per part d'aquelles que eren precedentment excloses de I'escolarització postobligatòria), com si és de "cicle llarg». ${ }^{13}$

A falta de dades segures és objectivament difícil afirmar quin dels dos comportaments és més recurrent a l'extraescola, especialment en el seu aspecte de doble posició. Malgrat això, és suficientment cert el predomini masculí en les distintes formes d'unió entre formació i treball (vegeu, al tespecte, les dades telatives a l'aprenentatge, taula 9).

Malgrat Ilur esquematicitat, aquestes poques dades (totes s'han de pro. funditzar) suggereixen el paper decisiu de la possessió o no d'escolaritat i de la certificació escolar en determinar i explicar els diversos comportaments en el camp formatiu, encara que, òbviament, aquests mateixos comportaments s'han de collocar dins d'un marc interpretatiu més ampli. Així, per citar només aquest exemple, és probable que la major propensió dels nois a freqüències irregulars i discontínues depengui, per una banda, de la crisi de llocs de treball, que ha baixat les expectatives formatives i de treball, i, per l'altra, de la seva major possibilitat de trobar feina (encara que sigui esporàdica) respecte a les dones (la demanda femenina no instruida de treball entre els 14 i els 19 anys resulta efectivament molt es. cassa). ${ }^{14}$

De totes maneres, hi ha el fet que la variable «escolaritat» (com un bé ja àmpliament posseït o no) serveix decididament per a explicar els dos comportaments. Així, com a curiositat, el comportament femení podria ésser explicat com una cursa cap a un «bé» no posseït precedentment (i més, dins d'un completiu procés d'autoafirmació), i el masculí com una actitud, diguem.ho així, «desencantada» davant de l'escola, fruit de la ja conquerida i posseïda escolarització, que indueix a posseir-ne una altra de posterior, a enriquir-la, a diferenciar-la en la certificació i fins en les ma. neres d'organitzar el camí formatiu.

13. Extremament indicatives són les dades de les taules 7 i 8 , tretes de «Cisem/ Informazioni», núm. 2, 1984, relatives als diversos índexs de fracàs (suspensos més renúncies) dels nois i les noies.

14. Cfr. Isofol, Rapporto Isofol $1982 \ldots$, cit., en particular el cap. 2. 


\subsection{Una possible clau interpretativa}

Quina versió és possible donar dels canvis que tenen lloc en la formació postobligatòria?

L'esquema interpretatiu que suggereixo $-\mathrm{i}$ que, ho vull dir amb cla* redat, opino que té encara necessitat de nombroses posades a punt- és que aquells canvis són conseqüència del progressiu aprofundiment de l'escolaritat; que una gran part del «nou» que està passant dins de la formació postobligatòria no indica men primera instància- eleccions difetents d'una ulterior escolarització, sinó un enriquiment i una nova definició de la mateixa escolarització; que els diversos fenòmens provenen, doncs, dels alts índexs d'escolaritat i dels nous mecanismes de funcionament de l'escola (que són, al mateix temps, respostes autònomes de la institució escola i fruit de comportaments subjectius dels usuaris). $O$ sigui que, segons la meva opinió, allò que tenim al davant nostre és una nova versió de l'«escolarització de massa» que no substitueix l'escola amb altres coses, sinó que proposa un escenari més ric $i$ articulat que en el passat dins del ter. reny de les necessitats, de les expectatives, de les exigències, dels instruments (formatius) i en el terreny de les «modalitats» de construcció dels camins escolars i educatius; escenari del qual l'escola i l'escolaritat contiguen essent el moment central, encara que aquesta centralitat té cada vegada menys coses a compartir amb les situacions i les versions precedents i necessita encara ésser compresa i definida.

Si volguéssim expressar tot això en forma de «categoria interpretativa», podriem dir que comencen a existir les conseqüencies i els problemes d'una situació de "plena escolaritat» (o d'«escolaritat madura») també a nivell postobligatori. Proposar aquesta com a categoria interpretativa, a més a més, no significa afirmar que la "plena escolatitat» estigui realitzada: no és aquest l'aspecte en el qual insistir, encara que algunes dades semblen confirmar aquesta lectura. Significa, més aviat, ifirmar que - com succeeix sovint- els problemes nous s'expressen «merttre» duren els vells i que això comporta que també aquests últims canviïn el seu caràcter, atès que ja poden ésser entesos i solucionats amb criteris que no tinguin en compte la direcció cap a on van les coses.

Significa, a més a més, proposar —com ja he dit —una aproximació vàlida essencialment a nivell interpretatiu, una aproximació que em veig amb cor de sostenir perquè presenta algunes característiques objectivament «útils»:

- La primera, la d'oferir una clau interpretativa menys superficial que aquella de la pèrdua de centralitat de l'escola, a favor d'altres solucions 
i d'altres instruments més capaços que aquesta última d'explicar el que passa, relacionats com poden ésser els diversos fenòmens amb correlacions concretes i no amb suposades capacitats dels joves a orientat-se $\mathrm{i}$ triar, dins de la «jungla» formativa.

- La segona, la de corregir l'altra manera d'afrontar les qüestions formatives, precisament la - per entendre'ns- de les forces reformadores, que s'han mogut sempre dins d'una "lògica» de mancança; per a aquesta l'objectiu ha estat sempre i fonamentalment la ulterior expansió de l'escolaritat, sense preocupar-se dels èxits del procés, fins $i$ tot quan aquests han començat -com ja fa uns anys- a manifestar-se i a proposar problemes que des d'aquella òptica es tornen incomprensibles.

- La tercera, la de presentar-se com a clau de lectura i d'intervenció vàtida, no sols per al present, sinó també per al futur immediat, atès que capta no tant la realitat com les tendències (i la direcció d'aquestes ten. dències) presents en ella.

\section{TRANSFORMACIO DEL SISTEMA EDUCATIU I POLITIC ESCOLAR: ALGUNES IDEES-GUIA PER A INTERVENIR-HI}

Desplacem el raonament cap a un altre cami, i considerem les conse. qüències de les anàlisis efectuades respecte a una possible política escolar i educativa. L'objectiu que em proposo és el de presentar algunes idees, algunes categoties, utilitzables per a intervenir-hi. Pot ésser també una manera de verificar l'estabilitat dels resultats obtinguts, o almenys de verificar-ne la productivitat.

Primer nus de problemes. Els desenvolupaments específics i completius de l'«escolaritat», encara que influïts per dades socials, polítiques, econòmiques, generals $i$ contingents, se'ns presenten, al mateix temps, corn a relativament «autònoms». La influència externa és més o menys important, en alguns casos explica uns determinats comportaments, pexò davant d'ella acaben per funcionar d'altres dades, algunes bastant fortes, totes internes als processos d'instrucció. Em refereixo especialment a la funció social de la possessió o no d'escolarització, que és, en molts casos, una força potent que actư fins en presència d'una àmplia desillusió respecte al valor (d'ús o d'intercanvi) de la instrucció.

Hem vist com això pot estar a la base dels diferents comportaments masculins i femenins. Però es poden recordar altres casos. En les situacions 
sòcio-territorials en les quals «anar a escola» és una elecció $i$ un fet present des de fa anys, podem constatar que - fins en presència de grans factors de crisi econòmica, però també per continuar amb el sistema edıcatiu, del desenvolupament $i$ d'altres oportunitats respecte a l'escolaaquesta tendència no sols continua expressant-st, sinó que àdhuc s'enforteix fins al Ilindar d'una teal i plena escolarització. ${ }^{15}$

D'altra banda no hi ha una gran novetat a subratllar aquestes coses, atès que sobre l'existència d'aquestes tendències i $d$ 'un fenomen que po. driem definit com de valorització autònoma de la instrucció han reflexionat --sostinguts per una gran quantitat de dades-- sociòlegs com Collins o Boudon $i$ economistes com Thuron $i$, en alguns casos, Hirsh. ${ }^{16}$

Però hi ha també altres factors a tenir en compte, menys explorats que els mencionats: l'«ús» que es fa de la instrucció per part dels diversos subjectes socials. Un ás que pot ésser interpretat, com fa per exemple Collins, com una manera de confirmat i consolidar la pròpia posició social per part de cada grup o categoria social, però que coneix cada vegada més valences individuals, acusadament subjectives, $i$, al mateix temps, relacions profundes amb els processos de creixement de nous subjectes político-socials, com els joves $i$ les dones, etc.

Per què aquest subratllar la relativa «autonomia» dels desenvolupa. ments de l'escolaritat? Perquè des del punt de vista de la política escolar i educativa això significa saber que hi ha dades inherents als mateixos processos d'escolarització que influeixen en el desenvolupament $i$ en la configuració del sistema formatiu tant, si més no, com uns factors externs considerats tradicionalment determinants.

Així hem vist, per exemple, que la crisi de la relació entre escola i treball no ha modificat la demanda d'escola i de formació: ha donat vida a nous camins, a noves relacions entre formació i experiències de treball, al

15. Es exemplar el cas de dues realitats com la de: Ravenna i Piacenza, que he pogut analitzar a fons. $\mathrm{L} a$ dada característica d'aquestes dues situacions no és constituïda sols pels altíssims índexs d'escolarització en els ptimers anys, aconseguits amb els primers anys 80 (comprovats entorn d'un $85 \%$ pel que fa referència tan sols a la secundària superior, excloent la FP), sinó pel fet que els fndexs eren ja elevats en la primera meitat dels anys 70 (comprovats entorn d'un $75 \%$ solament en l'escola se. cundària supetior: dada que sols actualment s'està assolint a escala nacional).

Maigrat la presència de la FP (i també de vistosos símptomes de crisi econòmica i de trebali, com en el cas de Ravenna), l'escolarització ha continuat aprofundint-se, posant en relleu de quina manera un comportament ja present des de fa temps $\mathrm{i}$ estès a nivell social pot influir $\mathrm{i}$ determinar - $-\mathrm{amb}$ caràcter d'autonomiales eleccions successives.

16. Vegeu al respecte les referències bibliogràfiques al treball «I possibili prodotti dell'istruzione» en aquest mateix libre. 
desenvolupament d'activitats formatives específiques; o sigui, ha provocat, si de cas, canvis en el recorregut del sistema, però al seu costat s'han confrmat $i$ profunditzat fenòmens que des d'aquella òptica particular podien convertir-se, de fet, en anacrònics. L'exemple és encara més ric de significats, si pensem en la profunda crisi del valor de la instrucció i especialment de l'escola i la comparem amb la gran demanda d'escola expressada per les dones en aquests últims deu anys: els desenvolupaments de l'es. colaritat, la configuració del sistema d'instrucció i formació, depenen àmpliament de factors interns a ells mateixos. És necessari que la política escolar i educativa aprengui a conèixer aquests factors, a tenir-los en compte en la definició dels objectius i de les finalitats, i especialment a valorar els seus efectes sobre el funcionament del sistema mateix.

Segon nus. Si les anàlisis que hem fet són exactes, el que passa en el sistema d'instrucció i formació no és una suma de fets i fenòmens inde. pendents $O$ parallels entre si. Al contrati, fins donant per descomptada una forta segmentació, l'absència de teixits de connexió visibles, el caràcter fortament, si no totalment, espontani dels diferents fenòmens, hem pogut retrobar nombroses relacions de causa i efecte, una genèrica coherència del funcionament completiu del sistema (i la nostra anàlisi - ho hem d'afirmar més d'una vegada - encara és parcial i necessita aprofundiment).

Són dues les dades importants relacionades amb aquest problema.

La primera consisteix a subratilar la categoria «funcionament com a sistema», que, pex una banda, resulta ésser una dada «operant», encara que sigui en formes espontànies $i$ contradictòries, mentre, per l'altra banda, es presenta com el terreny, diguem, «obligat» de qualsevol reflexió i intervenció respecte a l'escola i a la formació. La segona és el «centralisme» que els desenvolupaments escolars i el funcionament de l'escola tenen respecte al funcionament completiu del sistema de formació: donats aquells com a base, molts dels diferents desenvolupaments troben una explicació plausible, òbviament junt a les causes més generals que he anat tecordant. Així, per exemple, és possible veure l'existència d'una relació entre desenvolupaments presents en la secundària $i$ els canvis que tenen lloc en el sector de les escoles privades; entre sortides irregulars de la secundària $i$ inscripcions als cursos de formació professional; entre les mancances de la secundàtia $i$ el desenvolupament d'una part de les activitats de l'extraescola, $i$ així successivament.

Per què són importants aquestes dues dades? Petquè si per una banda hem dit que l'expansió del sistema formatiu postobligatori respon a problemes reals que com a tals hem de comprendre $i$ organitzar, atès que en ells s'expressa la moderna versió de la formació, l'anàlisi que hern comen. 
çat aquí ens ofereix instruments concrets de comprensió, en representar els diversos fenòmens com a concatenats, com a possibles efectes dels mateixos processos d'escolarització de massa arribats -com es deia- al llindar de Ia «plena escolaritat» o almenys de l'escolaritat àmplia.

Escola, extraescola, formació en el treball, molt lluny d'ésser moments separats, forma «tripartita» del sistema educatiu, poden, en canvi, ésser considerats com una cadena, com la forma actual, certament més complexa i rica que Ia d'ahir, de l'kescolaritzación de massa.

Tercer nus. Quines són les possibles idees-guia per a una intervenció de política escolar i educativa?

Presento alguns problemes; el primer de caràcter general, que exigeix que s'efectuil una reflexió teòrico-cultural més exhaustiva, els altres ja més particularitzats, o almenys més clars en Ilurs implicacions operatives.

La primera idea, fonamentalment, és reconèixet el paper central, però al mateix temps "parcial», de l'escola dins de l'escenari més ampli del sistema de formació postobligatòria. En la pràctica, no ha sigut així i no ho és: pensar en la reforma (per no fer-la mai) ha significat sempre proposar-se tota la temàtica formativa possible, intentar ajuntar molts objectius i moltes finalitats, encara que sovint molts d'ells estaven en contradicció entre si, o almenys era extremament ardu (al límit de la impossibi. litat) trobar un equilibri raonable. En canvi, és necessari ésser conscients de les possibilitats, de les necessitats de formació i especialització postetiors, $\mathrm{i}$ del fet que alguns objectius, com per exemple el d'una formació dirigida a la professionalitat, no poden ésset resolts sols per l'escola, sinó per l'escola juntament amb la formació professional i amb la formació en el treball: s'han d'utilitzar aquestes $i$ altres possibilitats ulteriors per preguntar-se quines són, en canvi, les característiques i les finalitats pròpies de l'escola, i per tant no delegables. Ptegunta molt més legitima i rica en significats si tenim en compte les transformacions que tenen lloc en el pla cultural i cientiffc, que, de fet, tornen a posar profundanent en crisi moltes de les funcions tradicionals de l'escola. Em limito a unes breus notes.

Els tecursos informatius de què disposem actualment, el previsible, colossal desenvolupament d'aquests recursos, la seva accessibilitat cada vegada més estesa, posen en discussió dràsticament la funció del lloc on es reben les informacions i els coneixements, que ba estat ( $i$ és) una de les característiques "històriques» de l'escola com a instrucció: sobre la seva base s'ha plasmat i estructurat l'escola. També per aquest cami, doncs, és inevitable un replantejament general de les tasques i de les característiques de I'escola. 
La segona idea consisteix a saber que els problemes actuals són de tipus més qualitatiu que quantitatiu. Amb això no vull pas dir que no existeixin zones d'endarreriment, situacions en les quals és necessari, encara, eixam* plar els processos d'escolatització; proposar-se metes de difusió més forta de la formació a nivell social és, fins i tot, un objectiu que haurà d'impregnar les noves orientacions en el camp educatiu. Però és veritat que hem superat la fase en la qual era necessari demanar sobretot l'expansió de l'escolaritat: el que cal actualment és pensar en la qualitat dels processos, donant-los substància, sortides, resultats, permetent-ne així el desenvolupa* ment successiu. És en aquesta clau que es poden proposar dues ulteriors idees-guia que, fins en el seu catàcter genèric, tenen el mèrit de transformat en cristallines les eleccions a fer.

La tercera idea és, doncs, la consolidació d'aquella que abans he anomenat «plena» o àmplia escolaritat.

Motivava aquest judici, per una banda, sobre la base dels alts nivells d'escolaritat en els primers dos anys de formació postobligatòria, per l'altra sobre el nombre sempre abundant d'aquells qui continuen $i$ arriben al final dels estudis, i finalment -aspecte poc analitzat- sobre el nombre d'aquells qui de totes maneres realitzen una conclusió dels estudis tant a través dels «retorns» com del pas a la formació professional, i així successivament. Les dades són reals, però no els corresponen solucions orgàniques: la frequiència en els primets anys no té lloc en un cicle formatiu/ educatiu que porti a un resultat (exceptuada la formació professional): es tracta d'una freqǜ̀ncia «gratuïta» sense memòria; els successius «passos» són absolutament espontanis, no previstos institucionalment: la conjunció amb la formació professional, per exemple, està feta, tota, a risc de l'usuari; l'institut del «retorn» no existeix. Consolidar els processos d'escolarització resulta ser, doncs, un dels objectius fonamentals de la reforma, i el que ja està passant ens ofereix, d'una banda, el material sobre el qual meditar $i$, per l'altra, condicions que ens poden facilitar l'arribada.

Poso un exemple: el bienni, com a cicle a part, també amb valença terminal, ${ }^{17}$ la conjunció amb la formació professional; una divisió horitzontal, per metes formatives (o fins $i$ tot per cicles) del trienni successiu, amb la indicació, aquí també, de les possibles conjuncions aptes per a consolidar l'especialitzacio a nivell intermedi (segons el meu parer no assolible

17. Sobre aquest argument, objecte, en el curs dels anys 70 , de moltes refiexions, em sembla que s'ha de remarcar, per la riquesa de les argumentacions i per l'actualització que es fa del problema, el treball de F. Frabboni aL'obbligo scolastico e il suo completamento», aparegut en dues parts a «Riforma della scuola», respectiva. ment als núms. 3 i $4,1984$. 
dins d'una escola que al mateix temps vol i ha d'ésser pre-universitària i moment escollit de la formació cultural, científica, tècnica, per graus cada vegada més elevats); la introducció de l'institut del «retorn», que una divisió "ćclica» dels cinc anys faria factible: molt esquemàticament i sols a nivell de títols, aquestes em semblen les coses dignes de reflexió.

La quarta idea -... que no sembli en contradicció amb el que acabem de dir- és la de la «diversificació»: la necessitat d'assegurat difetenciació, enriquiment, personalització, als processos d'escolarització. Actuen en aques. ta necessitat factors diversos: les propensions subjectives a construir-se camins formatius individualitzats, la versió de l'educació i de la formació com un procés continu que es va difonent cada vegada més i és ja implícit en molts dels desenvolupaments descrits abans, la relació amb un mercat de treball diferenciat $i$ segmentat, $i$ finalment la mateixa difusió dels títols d'estudi, que té com a consequèencia la seva progressiva pètdua de valor, fenomen, aquest últim, destinat a augmentar cada vegad̉a més amb la ulterior consolidació dels processos d'escolarització. Totes aquestes coses, com hem vist, ja estan actuant àmpliament i d'elles s'ocupa actualment el «lliure mercat» de la formació, constituït, quasi en la seva totalitat, per intervencions privades, recolzades en gran manera en l'immobilisme de l'escola (i del sector públic). El que desitjo subratllar és que ja actualment, però sobretot en un futur, aquesta funció de diversificació està destinada a ésser «estratègica», i el que és negatiu -almenys des del meu punt de vista- no és tant que aquesta funcío siģui prerrogativa del sector privat (la "gestió" de moltes activitats formatives pot tranquillament continuar essent privada), com que sobre ella no s'expressi cap lògica de «govern» (que opino que ha d'ésser $\mathrm{i}$ de continuat essent pública).

Una última reflexió: en aquest context, segons el meu parer, és molt ampli el paper que pot representar la formacić professional «regional», entesa, precisament, com a moment d'integracić, enriquiment, especialització dels currículums escolars: un paper actualment contrastat per les característiques i la dimensió de la formació professional de base, de fet una segona «escola» que absorbeix la màxima part dels recutsos financers.

Quart (i últim) nus. La gestió i el govern dels processos educatius i del sistema de formació; la «forma», els «caràcteıs», d'aquest govern.

El conjunt de les coses que estan passant és fruit d'orientacions i moviments espontanis. Compten moltes coses, internes $\mathrm{i}$ externes al sistema, en determinar la fenomenologia específica dels desenvolupamens i dels comportaments actuals, però la qualitat de les necessitats, la seva varietat $i$ variabilitat, l'enllaçament de dades objectives $i$ subjectives, ens presenten un 
quadre marcat per unes característiques estructurals: la dinamicitat, la flexibilitat, la discontinuitat, el canvi i la complexitat.

Hi ha dos aspectes a resoldre. El primer és el de la «gestió» d'aquest conjunt $\mathrm{i}$, contempotàniament, del «subjecte» (o dels subjectes) que haurà (o hauran) de tenir la capacitat, per una banda, de llegir $i$ analitzar els canvis i, per l'altra, d'orientar-los, coordinar-los, oferir-los sortides, etcètera.

Aquí hi ha un problema real i urgent a resoldre, absent del debat actual, un problema que modifica la maneta en què ha estat considerada fins aquí la qüestió de la gestió del sistema educatiu. En aquest cas ja no es tracta sols d'assegurar democràcia a la gestió d'aquest o aquell fragment del sistema de formació (encara que, òbviament, aquest problema roman); es tracta d'afrontar el problema del «govern» del conjunt i de replantejar-se sobre aquesta base conceptes com "centralisme» $i$ «descentralització».

Segon aspecte: Com es governa aquest conjunt? Amb quins instruments? Amb quin equilibri entre resposta institucional i moviment?

No tinc solucions, però a vegades ja és molt fer-se les preguntes. Sé el que tindria poc efecte: pensar a respondre exclusivament amb unes lleis, o sigui, amb respostes institucionals; $i$, al contrati, sento una necessitat molt forta d'un govern dels processos fundat en instruments i mecanismes des* centralitzats, capaços de fer conscients els usuaris de les eleccions (que són dinàmiques, no estàtiques) que estan a punt de fer $\mathrm{i}$ faran. Tot això requereix una nova reflexió sobre què són actualment participació i democràcia; sobre la relació entre «lleis» (i llurs característiques) i moviment, entre intervenció pública i privada, entesa en aquest cas no com a sector, sinó com a moviment real dels individus $i$ de la societat.

\section{Tavla 1}

Index de pas entre escola media/escola superior secundàtia segons repartiment geogràfic

\begin{tabular}{lcccc}
\hline Any & Nord & Centre & Sud & Itallia \\
\hline $1977-78$ & 66,6 & 82,9 & 79,6 & 74,2 \\
$1978-79$ & 69,5 & 81,5 & 77,2 & 74,5 \\
$1979-80$ & 68,7 & 81,8 & 77,6 & 74,3 \\
$1980-81$ & 68,8 & 81,5 & 76,5 & 73,9 \\
$1981-82$ & 70,1 & 82,7 & 77,1 & 75,0 \\
$1982-83$ & 71,7 & 83,6 & 78,0 & 76,2 \\
\hline
\end{tabular}

Fonts: Elaboracio Censis sobre dades Istat, a XVII rapporto 1983 sulla situazione sociale det paese, Aageli, Milano. 1983. 
Les noves formes de al'escolaritat» de massa

\section{TAULA 2}

Província de Milà. Index d'escolaritat de la classe 14 anys relativa al primer any de l'escola secundària supetior diürna (pública/privada)

\begin{tabular}{ccc}
1979.80 & $1980-81$ & $1981-82$ \\
\hline 73,8 & 74,9 & 76,4 \\
\hline
\end{tabular}

Font: Cisen Formazione post-obbligatoria. Rapporto sulla situazione formativa, Angeli, Milano, 1 y83.

\section{TAULA 3}

Província de Ravenna. fndex d'escolaritat en el 1r. i 2n. any d'escola secundàtia superior (pública/privada)

\begin{tabular}{rll}
\hline & 1r. any & $2 n$. any \\
\hline $1979-80$ & 82,10 & 65,98 \\
$1980-81$ & 83,25 & 66,77 \\
$1981-82$ & 84,24 & 66,01 \\
\hline
\end{tabular}

Font: Amm, prov, de Ravenna, Andamenti della formazione post-obbligatoria in provincia di Ravenns, 1973-1981, 1983, cicl.

\section{TAUla 4}

Index de renúncies en l'escola secundària superior des del primer any $\left(\mathrm{TA}_{1-2}\right)$ al segon, des del segon al tercer any (TA,3) i des del primer al tercer any $\left(\mathrm{TA}_{1-3}\right)$

\begin{tabular}{llll}
\hline Any escolar & $T A_{t-2}$ & $T A_{2-3}$ & $T A_{1-3}$ \\
\hline $1975-76$ & 13,6 & 6,5 & 21,6 \\
$1976-77$ & 15,5 & 5,9 & 19,6 \\
1977.78 & 17,1 & 8,5 & 22,7 \\
$1978-79$ & 18,1 & 8,9 & 24,5 \\
$1979-80$ & 18,2 & 9,1 & 25,6 \\
$1980-81$ & 19,7 & 9,4 & 25,9 \\
\hline
\end{tabular}

Font: «Cisem/Informazionin, núm. 2, 1984. 
«Papers»: Revista de Sociologia

\section{TAUla 5}

Index de fracàs des del primer any de curs a l'any final en els principals instituts

Institut tècnic industrial

Institut professional

Institut tècnic de geometria

Institut tècnic comercial

Liceu científic

Liceuı clàssic

Institut magistral
$\mathrm{TC}_{1-5} \quad 47,4$

$\mathrm{TC}_{1-3} \quad 43,1$

$\mathrm{TC}_{\mathrm{t} .5} \quad 33,0$

TC.5 $\quad 30,3$

$\mathrm{TC}_{1-5} \quad 22,3$

$\mathrm{TC}_{1.5} \quad 22,3$

$\mathrm{TC}_{1-4} \quad 19,0$
$\left(\mathrm{TC}_{1-3} \quad 32,6\right)$

$\left(\begin{array}{ll}\mathrm{TC}_{\mathrm{f}-3} & 28,9\end{array}\right)$

$\left(\begin{array}{ll}\mathrm{TC}_{1.3} & 24,6\end{array}\right)$

$\left(\begin{array}{ll}T_{1-3} & 13,8\end{array}\right)$

( $\left(\mathrm{TC}_{\mathrm{I}-3} \quad 7,1\right)$

$\left(\mathrm{TC}_{\mathrm{l} \cdot 3} \quad 24,1\right)$

Les dades es refereixen a les últimes sèries historiques completes disponibles. Per als instituts de duració de cinc anys, des del $1975-76$ al 1979.80; per als instituts de quatre anys, des del 1976-77 al 1979.80; per als instituts de tres anys, des del 1977.78 al 1979.80 .

Font: $\times$ Cisem/Informazionin, 1984.

\section{TAULA 6}

Alumnes segons títol d'estudi i edat (valors en percentatges)

\begin{tabular}{|c|c|c|c|c|c|c|}
\hline \multirow[b]{2}{*}{ Modalitat } & \multicolumn{6}{|c|}{ Edat (anys) } \\
\hline & Fins a 16 & $77-18$ & 19.20 & $21-25$ & Més de 25 & Total \\
\hline \multicolumn{7}{|l|}{ Ultima classe freqüentada } \\
\hline Fins 5a. elemental ..... & 1,6 & 2,4 & 5,9 & 8,8 & 22,6 & 2,9 \\
\hline Primera mitjana ............... & 1,0 & 0,9 & 0,8 & 0,6 & 0,9 & 0,9 \\
\hline Segona mitjana $\quad \ldots \ldots \ldots \ldots \ldots$ & 1,7 & 2,3 & 1,3 & 1,1 & 1,3 & 1,8 \\
\hline Tercera mitjana $\ldots \ldots \ldots \ldots \ldots$ & 79,3 & 57,5 & 36,8 & 20,3 & 27,3 & 67,5 \\
\hline 2a.-2a. supetior $\ldots \ldots \ldots \ldots, \ldots$ & 14,0 & 31,8 & 27,8 & 8,8 & 5,5 & 194 \\
\hline 3a-4a.-5a. superior,$\ldots \ldots \ldots \ldots$ & 0,2 & 2,8 & 22,7 & 38,8 & 17,0 & 3,9 \\
\hline Universitat $\quad \ldots \ldots \ldots \ldots \ldots \ldots \ldots$ & 0,1 & 0,1 & 1,6 & 13,4 & 13,9 & 0,9 \\
\hline No indicat $\ldots \ldots \ldots \ldots \ldots \ldots \ldots$ & 2,1 & 2,2 & 3,1 & 8,2 & 11,5 & 2,7 \\
\hline Total .......... & 100,0 & 100,0 & 100,0 & 100,0 & 100,0 & 100,0 \\
\hline
\end{tabular}

Font: Isfol, consistenza e caratteristiche del sistema di formazione professionalen, Quaderni di formazione Isfol, n. 77. 


\section{Taula 7}

fndex de fracàs masculí $i$ femení en els primers tres anys d'escola secundària superior

\begin{tabular}{llr}
\hline & $M$ & \multicolumn{1}{c}{$F$} \\
\hline Del primer al segon any $\ldots \ldots \ldots \ldots$ & 23,6 & 17,5 \\
Del segon al tercer any $\ldots \ldots \ldots \ldots$ & 11,5 & 9,7 \\
Del primer al tercer any $\ldots \ldots \ldots \ldots$. & 32,4 & 25,5 \\
\hline
\end{tabular}

TaUla 8

fndex de fracàs masculí i femení des del primer any de curs a l'any final en els principals instituts

\begin{tabular}{|c|c|c|c|}
\hline & & $M$ & $F$ \\
\hline Institut tècnic industrial $\ldots \ldots \ldots \ldots \ldots \ldots$ & $\left(\mathrm{TC}_{\mathrm{l} .5}\right)$ & 47,5 & 45,0 \\
\hline Institut professional $\ldots \ldots \ldots \ldots \ldots \ldots \ldots$ & $\left(\mathrm{TC}_{-3-3}\right)$ & 44,4 & 41,7 \\
\hline Institut tècnic de geometria $\ldots . \ldots \ldots \ldots$ & $\left(T C_{1.5}\right)$ & 32,9 & 33,9 \\
\hline Institut tècnic comercial $\ldots \ldots \ldots \ldots \ldots \ldots$ & $\left(T C_{1.5}\right)$ & 33,6 & 27,3 \\
\hline Liceu científic . .......................... & $\left(\mathrm{TC}_{1-5}\right)$ & 21,5 & 21,6 \\
\hline 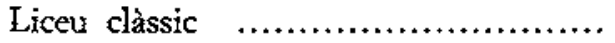 & $\left(\mathrm{T}\left(\mathrm{C}_{1-5}\right)\right.$ & 16,3 & 13,6 \\
\hline
\end{tabular}

Font: Istat. 
«Papers»: Revista de Sociologia

\section{TAula 9}

Aprenents ocupats per sector d'activitat econòmica i segons sexe el 1980 (valors en percentatges)

\begin{tabular}{|c|c|c|c|c|}
\hline \multirow[b]{2}{*}{ Secior d'activitat econòmica } & \multicolumn{4}{|c|}{ Aprenents ocupats } \\
\hline & $M$ & $F$ & $M F$ & Total \\
\hline 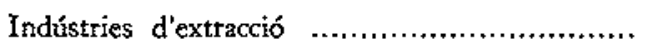 & 88,6 & 11,4 & 100,0 & 446 \\
\hline 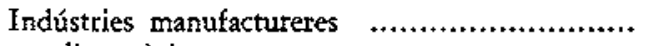 & 63,9 & 36,1 & 100,0 & 495.328 \\
\hline _- alimentàries ......................................... & 57,6 & 42,4 & 100,0 & 19.818 \\
\hline 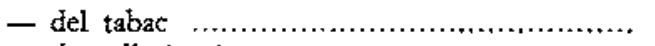 & 41,1 & 48,9 & 100,0 & 197 \\
\hline - de pells i cuir ..................................... & 35,1 & 64,9 & 100,0 & 17.838 \\
\hline 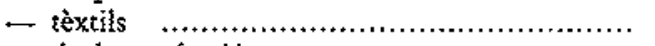 & 29,2 & 70,8 & 100,0 & 13.368 \\
\hline 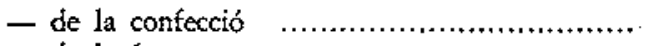 & 20,0 & 80,0 & 100,0 & 117.541 \\
\hline 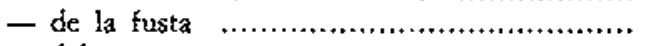 & 82,4 & 17,6 & 100,0 & 44.344 \\
\hline 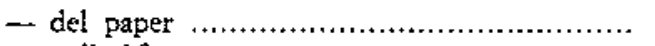 & 45,8 & 54,2 & 100,0 & 7.515 \\
\hline 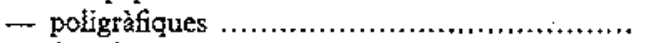 & 70,9 & 29,1 & 100,0 & 19.181 \\
\hline 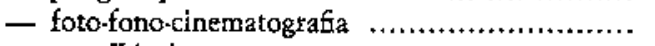 & 51,4 & 48,6 & 100,0 & 3.779 \\
\hline 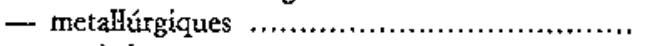 & 90,5 & 9,5 & 100,0 & 17.329 \\
\hline 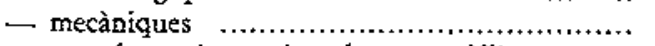 & 89,6 & 10,4 & 100,0 & 194.761 \\
\hline - transformacions minerals no metàlliques ...... & 69,9 & 30,1 & 100,0 & 12.471 \\
\hline 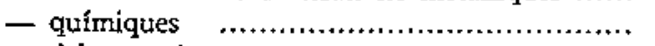 & 60,6 & 39,4 & 100,0 & 13.976 \\
\hline 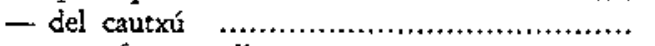 & 64,8 & 35,2 & $\pm 00,0$ & 3.795 \\
\hline- manufactures diverses ................................. & 60,8 & 39,2 & 100,0 & 9.615 \\
\hline Indústries construtcció ................................ & 96,8 & 3,2 & 100,0 & 82.216 \\
\hline Energia elèctrica, gas, aigua .......................... & 91,1 & 8,9 & 100,0 & 5.633 \\
\hline 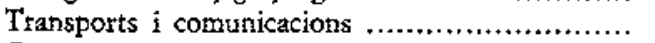 & 71,7 & 28,3 & 100,0 & 2.259 \\
\hline Comerç & 46,9 & 53,1 & 100,0 & 90.600 \\
\hline 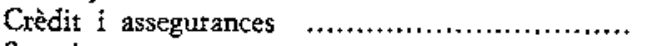 & 31,5 & 58,5 & 100,0 & 5.511 \\
\hline 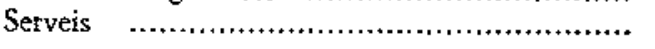 & 37,9 & 6,1 & 100,0 & 56.200 \\
\hline Total & 63,5 & 36,5 & 100,0 & 738.193 \\
\hline
\end{tabular}

Font: Elaboració Isofol sobre dades del treball. 